\section{ECCOMAS}

Proceedia
COMPDYN 2021

$8^{\text {th }}$ ECCOMAS Thematic Conference on Computational Methods in Structural Dynamics and Earthquake Engineering

M. Papadrakakis, M. Fragiadakis (eds.) Streamed from Athens, Greece, 28 - 30 June 2021

\title{
SEISMIC BEHAVIOR OF ARCHAEOLOGICAL MULTIDRUM COLUMNS AT THE POMPEII SITE
}

\author{
F. Autiero $^{1 *}$, G. De Martino ${ }^{1}$, M. Di Ludovico ${ }^{1}$, A. Prota $^{1}$ \\ ${ }^{1}$ Department of Structures for Engineering and Architecture, University of Naples Federico II, Italy \\ e-mail: francesca.autiero@unina.it \\ giuseppina.demartino2@unina.it \\ diludovi@unina.it \\ aprota@unina.it
}

\begin{abstract}
Free-standing multidrum stone columns are widespread elements in archaeological areas. The present study aims at investigating the behavior of these elements under seismic excitations. The dynamic behavior of free-standing multidrum columns is greatly affected by geometrical properties, constitutive materials, state of preservation, and amplitude and frequency of the seismic action. The first step of the research involved a wide and detailed survey for the definition of the mean geometrical properties affecting the seismic behavior of these columns in the archeological Pompei site. To this end, a wide range of grey-tuff columns (103 elements) from four different areas of the site involving private and public areas, were investigated. Then, numerical analyses were carried out based on the Finite Element Method (FEM) to investigate the seismic behavior of such elements. A column from the tetrastyle atrium of Casa del Fauno was selected for the analysis. The house is one of the largest and most visited private buildings at the Pompeii archeological site. The selected column presented deep degradation and needed specific and urgent attention for its assessment. In the following, the detailed survey and the modeling phases of the investigated element are described and the outcomes of the numerical analysis are reported and discussed.
\end{abstract}

\section{Keywords}

Pompeii archaeological site; cultural heritage; multidrum stone columns; geometrical properties; seismic assessment 


\section{INTRODUCTION}

Understanding the seismic behavior of typical ancient structures is crucial for the conservation of historical and archaeological assets. In particular, many important Greek and Roman archaeological sites are located in the Mediterranean area which is characterized by a notable seismic activity.

Columns are typical elements of ancient Greek and Roman architecture. In many cases, they were built with dry-overlapped stone pieces, namely the drums, placed above a stylobate, and typically carrying the load transmitted by a stone architrave or a wooden beam. Nowadays, multidrum stone columns are often free-standing elements, i.e. with no axial load except for their self-weight.

When subjected to a seismic motion, the single drums can rock and slide independently or in groups, resulting in a complex and highly non-linear behavior of the whole column. The first systematic and landmark study on the analysis of the rocking response of a single rigid block was proposed by Housner in 1963 [1]. From then, numerous investigations focused on the analysis of the dynamic response of free-standing multidrum columns, by following analytical [2-5], experimental [6,7], or more recent numerical approaches [8-11]. The main findings of these studies can be summarized in the following points: i) when subjected to seismic excitation, multidrum columns show many patterns of the rocking motion, whose number increase with the number of constituent blocks, and continuously move from one of them to another, thus natural modes of vibration in the classical meaning cannot be defined [12]; ii) the dynamic behavior of these elements is extremely sensitive to even trivial changes of the parameters of the structure or seismic input; iii) the slenderness and size of the columns affect their stability, with the higher slenderness, the higher the probability of collapse, and the higher size, for the same slenderness, the higher the stability; iv) low-frequency earthquakes are generally more dangerous than high-frequency ones $[2,4,11,13]$. Moreover, it was found that this type of structure, if well-preserved, is generally able to sustain notable seismic inputs $[8,12]$. However, typical forms of degradation can significantly affect the state of preservation and the stability of these elements. These are: material degradation; the presence of cracks; missing portions; deterioration of the contact surfaces among the drums; uneven profile of the column; misplaced drums after their re-erection; permanent relative displacements among the drums caused by past seismic events.

This paper presents a part of a wide study aimed at the investigation of the seismic vulnerability of free-standing multidrum tuff columns at the Pompeii archaeological site. This was a part of a scientific collaboration between the Archaeological Pompeii Park (PAP) and the Department of Structures for Engineering and Architecture (DiSt) of the University of Naples Federico II aimed to support the monitoring of the state of preservation of the columns at the site and the development of programs of interventions. The investigation included 103 columns from four different areas of the site. The first phase of the research involved detailed surveys, archival researches and visual inspections to define the main geometrical properties of the columns and the most common forms of degradation and damage, that may affect their seismic behavior. After that, an analysis of the seismic behavior of such structures was implemented with a column from one of the largest and most visited private buildings at the site, Casa del Fauno. Indeed, when the investigation has been started, the selected column presented deep degradation and needed specific and urgent attention for its assessment. The study was carried out based on the Finite Element Method (FEM). Eight seismic records were selected for the analyses, to investigate the influence of different frequencies and amplitudes of the seismic input. The following sections firstly focus on the main geometric characteristics and common forms of degradation of the Pompeian multidrum tuff columns; then discuss the modeling phases of the investigated element and the outcomes of the numerical analyses.

\section{FREE-STANDING MULTIDRUM TUFF COLUMNS}

According to the results of previous studies, the main geometrical properties and the state of preservation of multidrum columns significantly affect their seismic response $[1,12]$. Therefore, the following sections present the results of a systematic and detailed survey of a wide number of 
multidrum stone columns representative of a typical typology at the Pompeii archaeological site. In particular, free-standing Corinthian and Doric tuff columns were studied.

\subsection{Localization of the columns}

This part of the investigation involved structures from four different private and public areas of the site: a private house at Regio VI, Casa del Fauno (CF) and public areas at Regio VIII, Quadriportico dei Teatri (Q), Palestra Sannitica (PS), and Foro Triangolare (FT) (Figure 1). Note that the picture related to the Tetrastyle atrium of Casa del Fauno predates the recent restoration intervention (January 2021), that allowed removing the lateral supporting props shown in the picture.

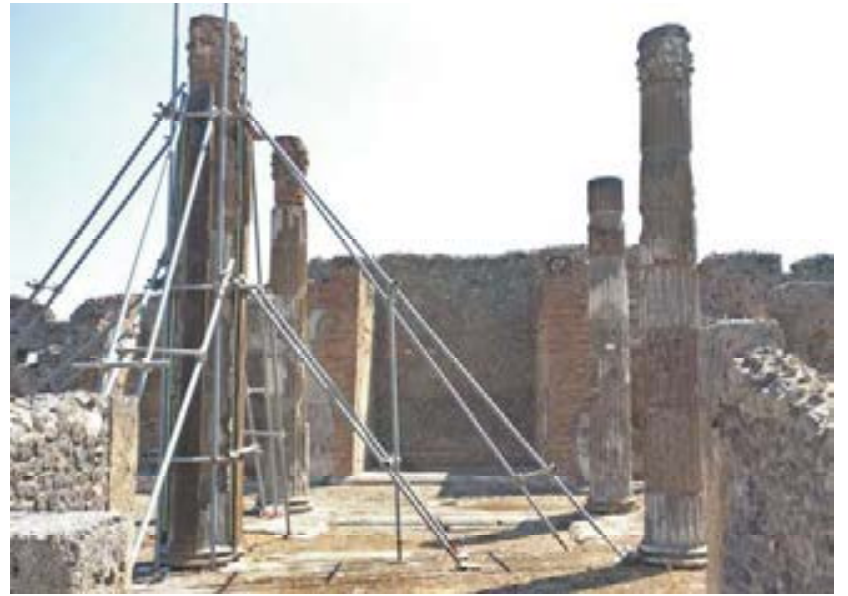

Tetrastyle atrium, Casa del Fauno (CF), Regio VI, Insula 12.

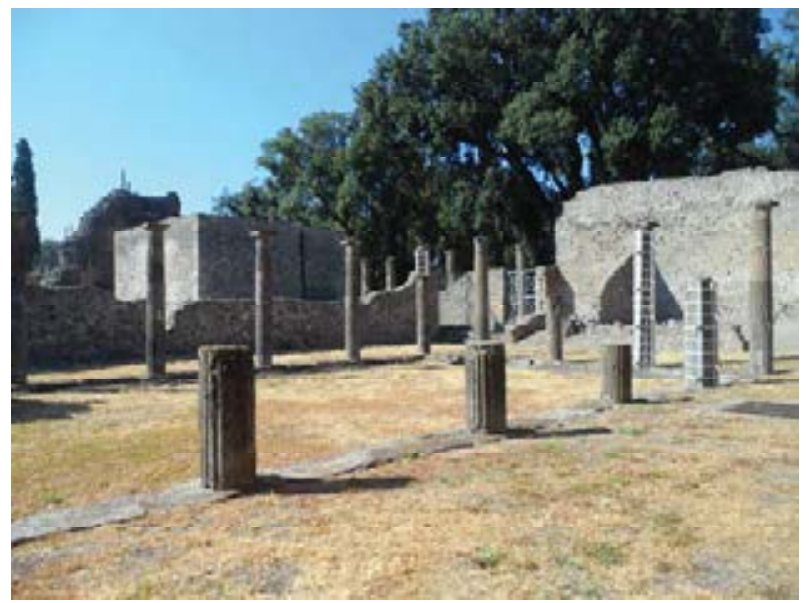

Palestra Sannitica (PS), Regio VIII, Insula 7.

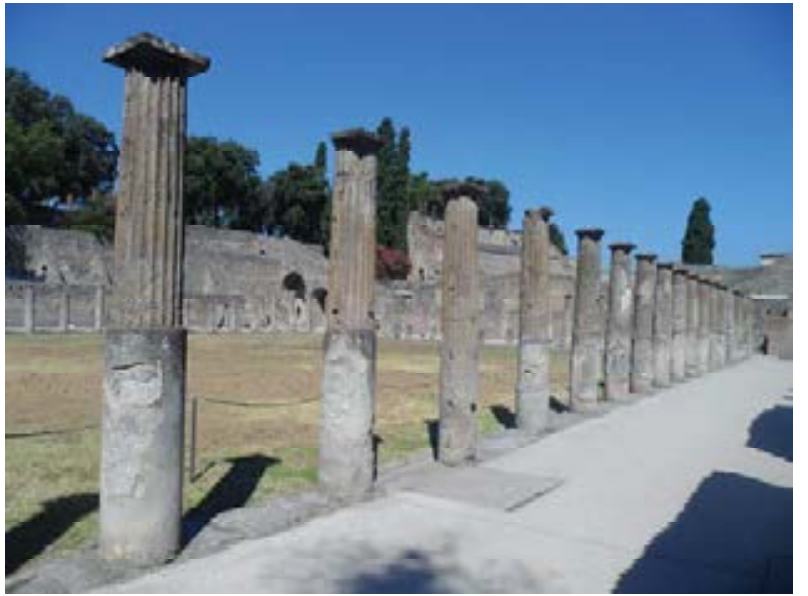

Quadriportico dei teatri (Q), Regio VIII, Insula 7.

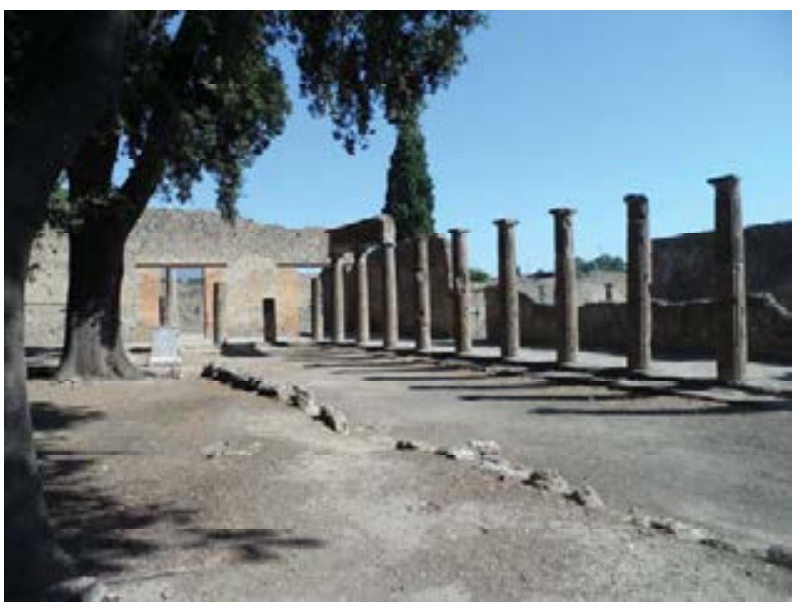

Foro triangolare (FT), Regio VIII, Insula 7.

Figure 1: Research areas.

As shown in Figure 1 several columns are incomplete and in a state of ruins. This was probably related to the fact that throughout the excavation and/or the execution of later interventions certain parts were significantly damaged. In detail, 55 out of 103 columns were complete, i.e. all the parts from the base to the capital stand today, while the other 48 columns were incomplete, i.e. had missing parts. One incomplete column was found at the tetrastyle atrium of the Casa del Fauno, for which only the capital was missing. Table 1 reports the total number of investigated columns for each area and the relative numbers of complete and incomplete elements. 
Table 1: Number of investigated columns for each area and complete and incomplete elements.

\begin{tabular}{lccccc}
\hline & CF & Q & PS & FT & Total \\
\hline number of free-standing columns & 4 & 54 & 19 & 26 & 103 \\
number of complete columns & 3 & 28 & 13 & 11 & 55 \\
number of incomplete columns & 1 & 26 & 6 & 15 & 48 \\
\hline
\end{tabular}

\subsection{Geometry and state of preservation}

The slenderness and the size of a column greatly affect its dynamic response $[1,12,13]$. The number of constituting drums is also relevant because it affects the energy dissipation due to friction. Literature studies showed that, on hard soil, it is possible to observe the effect of higher stability for a higher number of drums $[8,10]$.

Table 2 summarizes the mean geometric parameters and mass of the investigated complete columns. In particular, Table 2 reports: the total height, $\mathrm{H}$; the diameter at the base, $\mathrm{d}$; the aspect ratio, $\mathrm{H} / \mathrm{d}$, which is a measure of the column slenderness; the quote of the center of mass, $\mathrm{y}_{\mathrm{CM}}$; the distance from the center of mass of the column to the circumference at the base, $R$, which is a measure of the column size; the number of drums; the volume; the mass.

Table 2: Main overall characteristics of the complete columns.

\begin{tabular}{lcccc}
\hline & CF & Q & PS & FT \\
\hline Total height, $\mathrm{H}[\mathrm{m}]$ & 5.74 & 3.56 & 3.30 & 3.99 \\
Diameter at the base, d [m] & 0.71 & 0.49 & 0.39 & 0.53 \\
Aspect ratio, H/d [-] & 8.09 & 7.27 & 8.53 & 7.50 \\
Quote of the center of mass, ycm [m] & 2.79 & 1.70 & 1.58 & 1.88 \\
Distance center of mass - base perimeter, R [m] & 2.82 & 1.72 & 1.59 & 1.90 \\
Number of drums & 6 & 5 & 5 & 5 \\
Volume, $\mathrm{V}\left[\mathrm{m}^{3}\right]$ & 1.70 & 0.63 & 0.37 & 0.85 \\
Mass, $\mathrm{M}[\mathrm{kg}]$ & 4407 & 1634 & 972 & 2214 \\
\hline
\end{tabular}

The presence of material degradation and damage must be also taken into account for structural modeling since they can significantly alter the dynamic response of a multidrum column. Common forms of degradation and damage were found among the investigated columns at the Pompeii site: the presence of cracks; missing portions; contact surface between the drums reduced by weathering, the presence of invasive and incompatible interventions (see Figure 2). 


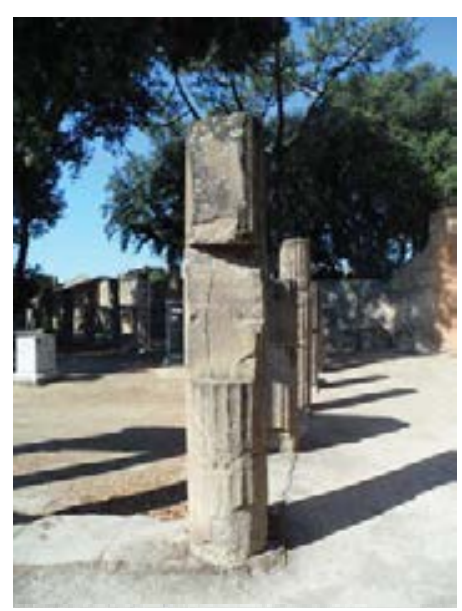

(a)

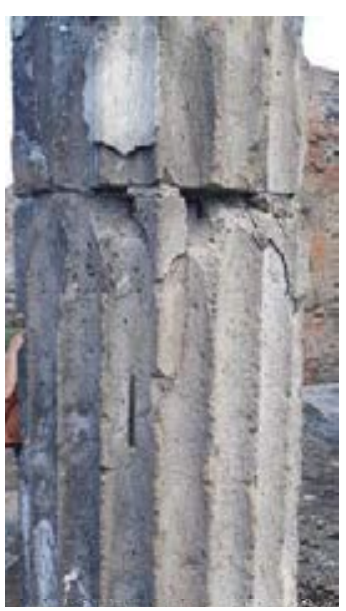

(b)

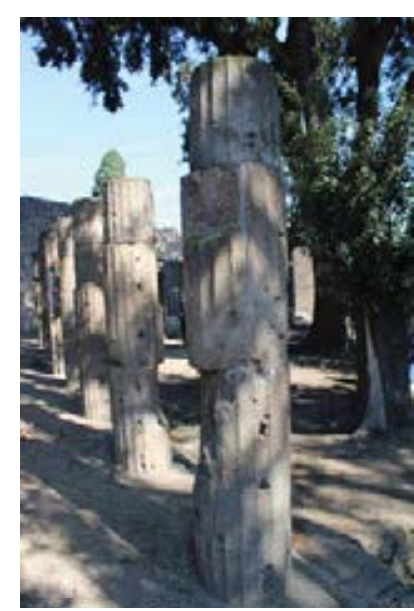

(c)

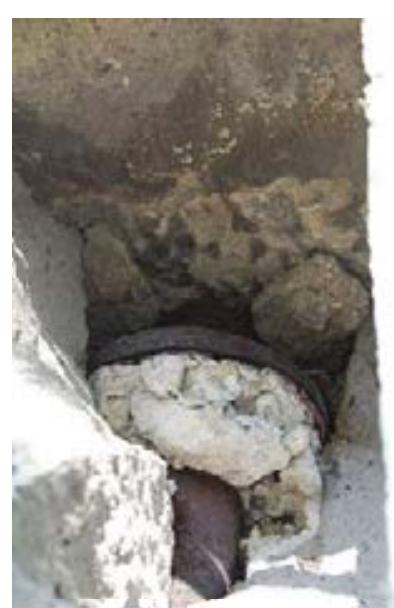

(d)

Figure 2: Most common imperfections, damage and deterioration forms in the columns: the presence of cracks, missing portions, reduced contact surface between the drums (a), (b), (c), invasive and incompatible interventions (b), and $(\mathrm{d})$.

\section{INVESTIGATION OF THE SEISMIC RESPONSE OF MULTIDRUM COLUMNS}

\subsection{Description of the model}

The analyses herein presented refer to one column at the Casa del Fauno. The analyses were carried out with finite element modeling (FEM), by using the software Abaqus/CAE. Therefore, the column was modeled as an assembly of overlapping deformable blocks, i.e. the drums. The geometric characteristics used in the model are listed in Table 3.

Table 3: Geometrical parameters used in the model.

\begin{tabular}{cccc}
\hline \multicolumn{4}{c}{ Free-standing multidrum column at the Casa del Fauno } \\
\hline & $\mathrm{h}[\mathrm{m}]$ & $\mathrm{d}_{\text {inf }}[\mathrm{m}]$ & $\mathrm{d}_{\text {sup }}[\mathrm{m}]$ \\
\hline drum 1 & 0.55 & 0.73 & - \\
drum 2 & 0.99 & - & - \\
drum 3 & 0.11 & - & - \\
drum 4 & 0.76 & - & - \\
drum 5 & 0.17 & - & 0.66 \\
capital & 0.67 & 0.66 & 0.66 \\
column & 5.72 & 0.73 & 0.66 \\
\hline
\end{tabular}

Each drum was modeled as an isotropic and elastic semi-conical solid (Figure 3 (a)) with material properties defined based on information from the technical archive of the Pompeii archeological site (Table 4).

Table 4: Material parameters used in the model.

\begin{tabular}{lc}
\hline \multicolumn{2}{c}{ Grey tuff } \\
\hline Bulk density, $\rho\left[\mathrm{kg} / \mathrm{m}^{3}\right]$ & 1230 \\
Elastic modulus, $\mathrm{E}[\mathrm{GPa}]$ & 4.5 \\
Poisson ratio, $v$ & 0.25 \\
Coefficient of friction, $\mu$ & 0.5 \\
\hline
\end{tabular}


The discretization of each drum was performed with 8-node hexahedra elements (Figure 3 (c)). Each drum was partitioned into eight portions, to obtain a regular and correct formation of the meshes (Figure $3(b)$ ).

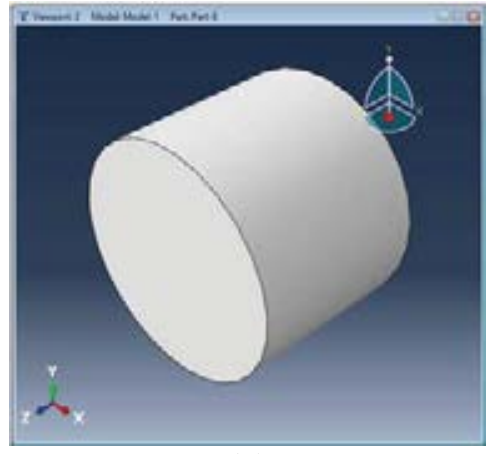

(a)

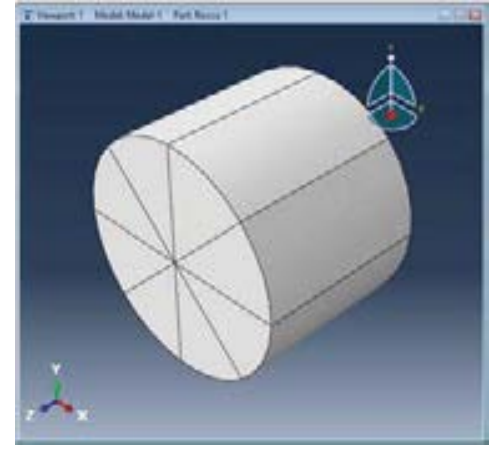

(b)

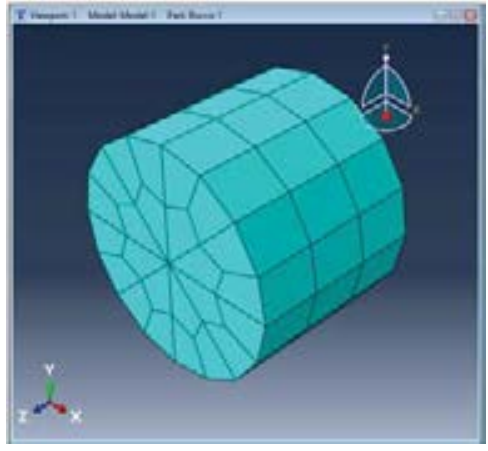

(c)

Figure 3: The geometric model of a drum: semi-conical solid (a), partition in eight parts (b), and mesh configuration (c).

The contact interaction between two consecutive drums was considered as governed by friction. Thus, it was modeled by adopting the Mohr-Coulomb criterion for the tangential stress along the surfaces, with dynamic coefficient friction equal to the static one (i.e. 0.5). This was consistent with the assumption made in other literature studies showing that the value of the dynamic coefficient friction has a negligible role in the analyses to capture columns seismic behavior $[8,13]$. Moreover, the hard contact behavior was set for the interaction between the drums in the normal direction, with compressive stress developed on the contact surface between two drums and zero stress when the drums are not in contact. Finally, the interactions between consecutive drums and between the first drum and the base of the column were defined by a "master" surface and a "slave" surface. A boundary condition of fully fixed connection was applied at the base of the column as well as the input seismic signals. Figure 4 shows the geometric assembly of the entire column; the defined interactions between adjacent surfaces; the boundary condition of fully fixed connection at the base; the application of a seismic input at the base; the final numerical model of the column with meshes.

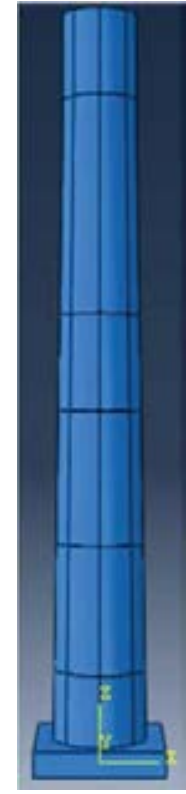

(a)
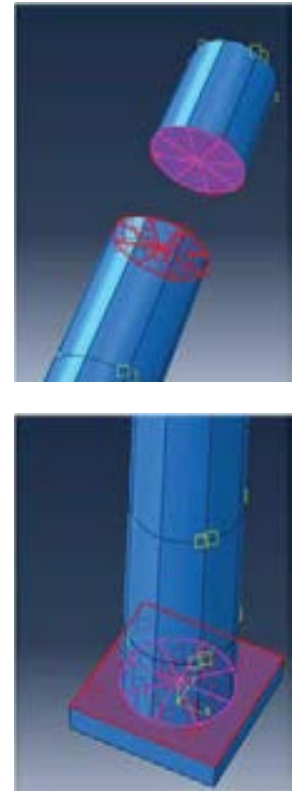

(b)

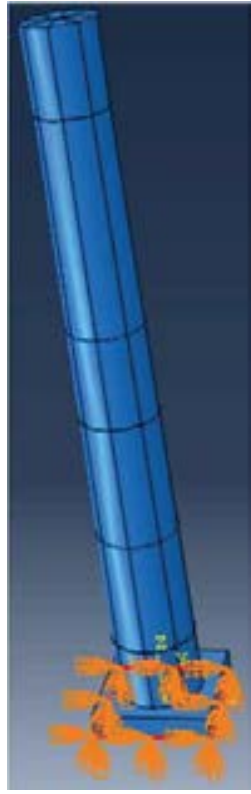

(c)

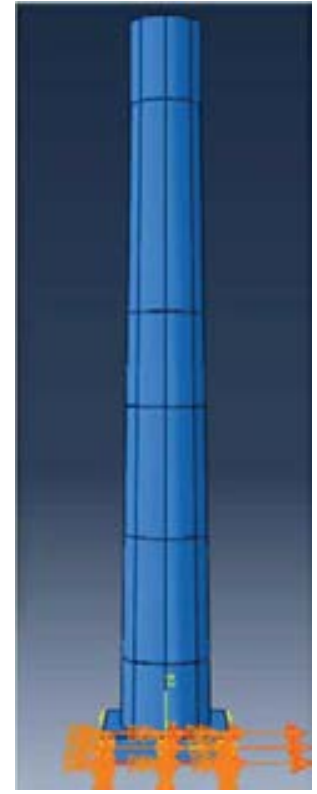

(d)

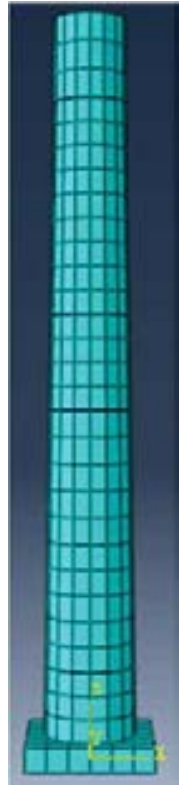

(e)

Figure 4: Phases of the modeling process: assembling of the single parts of the column (a); definition of the interactions between adjacent surfaces (b); definition of the boundary condition at the base (c); application of the seismic input at the base (d); final numerical model of the column with meshes (e). 
Each analysis involved two steps: the assignment of the geometrical and material properties, interactions and the acceleration of gravity; and the seismic input signal applied at the base of the column. The analyses were performed according to the dynamic implicit method, with the time of each step set equal to $0.005 \mathrm{~s}$. This latter was equal to the time step of the selected seismic records.

\subsection{Seismic input motions}

Eight seismic records with different frequencies and amplitudes were selected for the analyses: i) Irpinia, Italy (1980), recorded at Sturno, close to the epicenter and ii) Irpinia, Italy (1980), recorded at Torre del Greco, about 15km from Pompeii; iii); Molise, Italy (2002), recorded at San Severo, about $50 \mathrm{~km}$ from the epicenter; L'Aquila, Italy (2009), recorded at v. Aterno - Centro Valle, close to the epicenter; Kalamata, Greece (1986), recorded at Kalamata; Edessa, Greece (1990), recorded at Edessa; Aigio (1995), recorded at Aigio; Athens, Greece (1999), recorded at Athens. Table 5 reports the intensity measures and frequency content indicator of the seismic input motions selected for the analysis. In particular, the intensity measures PHA, PHV and PHD represent the maximum vector sums of the accelerations, velocities and displacements, respectively, in the two horizontal directions of the seismic records. The predominant period, $\mathrm{T}_{\mathrm{g}}$, was evaluated as the period corresponding to the maximum ordinate of the $5 \%$ damped pseudo-velocity spectrum.

Table 5: Intensity measures and frequency content indicator of the seismic input motions selected for the analysis.

\begin{tabular}{cccccccccc}
\hline Seismic record & $\begin{array}{c}\text { PGA } \\
{[\mathrm{g}]}\end{array}$ & $\begin{array}{c}\text { PGV } \\
{[\mathrm{cm} / \mathrm{s}]}\end{array}$ & $\begin{array}{c}\text { PGD } \\
{[\mathrm{cm}]}\end{array}$ & $\begin{array}{c}\text { PHA }^{*} \\
{[\mathrm{~g}]}\end{array}$ & $\begin{array}{c}\text { PHV }^{*} \\
{[\mathrm{~cm} / \mathrm{s}]}\end{array}$ & $\begin{array}{c}\text { PHD* } \\
{[\mathrm{cm}]}\end{array}$ & $\begin{array}{c}\text { E-W } \\
\text { E-W }\end{array}$ & $\begin{array}{c}\mathrm{N}-\mathrm{S} \\
\text { mean }\end{array}$ \\
\hline Irpinia_Str & 0.32 & 70.0 & 27.8 & 0.33 & 72.2 & 27.8 & 3.00 & 3.20 & 3.10 \\
Irpinia_TdG & 0.06 & 8.1 & 6.1 & 0.06 & 8.8 & 7.1 & 6.49 & 0.67 & 3.58 \\
L'Aquila & 0.66 & 42.7 & 6.8 & 0.77 & 46.7 & 6.8 & 0.67 & 0.50 & 0.58 \\
Molise & 0.06 & 2.1 & 0.3 & 0.06 & 2.4 & 0.3 & 0.50 & 0.38 & 0.44 \\
Kalamata & 0.27 & 31.7 & 6.5 & 0.35 & 38.5 & 6.7 & 0.67 & 0.55 & 0.61 \\
Edessa & 0.10 & 11.2 & 1.1 & 0.11 & 12.0 & 1.2 & 0.67 & 0.70 & 0.68 \\
Aigio & 0.52 & 51.3 & 8.3 & 0.53 & 51.3 & 8.6 & 0.55 & 0.55 & 0.55 \\
Athens & 0.31 & 16.9 & 2.1 & 0.38 & 16.3 & 2.9 & 0.65 & 0.22 & 0.44 \\
\hline
\end{tabular}

*The maximum vector sum of the two relative components

**Predominant period corresponding to the maximum ordinate of the $5 \%$ damped relative velocity spectrum

\section{RESULTS AND DISCUSSION}

The model of the column of Casa del Fauno was excited with the eight selected seismic records. To define the maxim ground acceleration sustained by the column for each seismic input without collapsing, a specific parametric analysis was performed by progressively increasing a scale factor applied to the intensities of the seismic records. Indeed, for each seismic input, the minimum value of the scaling factor leading to the collapse of the column was determined. Table 6 summarizes the outcomes of the analyses in terms of parameters of the seismic input motions leading to the collapse of the column and the number of collapsed drums beside the capital. 
Table 6: Parameters of the seismic input motions leading to the collapse of the column.

\begin{tabular}{cccccl}
\hline Seismic record & Scaling factor & $\begin{array}{c}\text { PHA } \\
{[\mathrm{g}]}\end{array}$ & $\begin{array}{c}\text { PHV } \\
{[\mathrm{cm} / \mathrm{s}]}\end{array}$ & $\begin{array}{c}\text { PHD } \\
{[\mathrm{cm}]}\end{array}$ & Collapsed parts \\
\hline Irpinia_Str & 0.5 & 0.17 & 36 & 13.9 & Capital and 2 drums \\
Irpinia_TdG & 4 & 0.24 & 35 & 28.2 & Capital and 4 drums \\
L'Aquila & 1.5 & 1.16 & 70 & 10.2 & Capital and 2 drums \\
Molise & 16.8 & 1.01 & 41 & 5.6 & Capital and 2 drums \\
Kalamata & 1.1 & 0.38 & 42 & 7.4 & Capital and 3 drums \\
Edessa & 3.45 & 0.38 & 41 & 4.2 & Capital and 2 drums \\
Aigio & 1.05 & 0.55 & 54 & 9.0 & Capital and 2 drums \\
Athens & 3.3 & 1.24 & 54 & 9.5 & Capital and 1 drum \\
\hline
\end{tabular}

The studied column showed different dynamic responses for the different input motions. Seismic motions with the higher predominant periods were found to be more dangerous, leading to the collapse with lower values of PHA, and confirming fundamental conclusions found in previous numerical and experimental studies [11,12]. Indeed, two records of the Irpinia earthquake, characterized by a high value of $\mathrm{T}_{\mathrm{g}}$, led to the collapse with the lowest intensities. Moreover, according to Italian territorial classification [14], the Pompeii site falls in a seismic zone whose acceleration with a probability of exceeding equal to $10 \%$ in 50 years ranges between $0.15 \mathrm{~g}$ and $0.25 \mathrm{~g}$. Therefore, considering the maximum vectorial sum, PHA, ranging between $0.21 \mathrm{~g}$ and $0.35 \mathrm{~g}$, only the two records of the Irpinia earthquakes produced PHA at the collapse falling in this range or below it. Figure 5 plots the value of the PHA that produced the collapse of the column for each seismic record, represented by the value of its predominant period, and the range of expected PHA derived by Italian seismic classification.

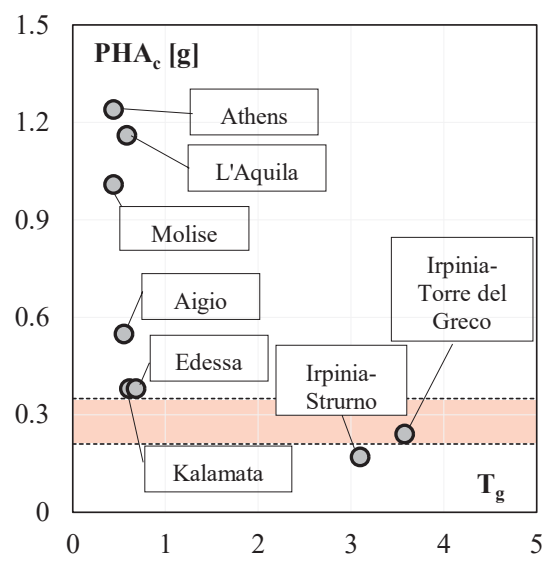

Figure 5: PHA that produced the collapse of the column for each value of the predominant period corresponding to the different seismic inputs and range of expected PHA derived by Italian seismic classification.

The responses were characterized by different combinations of relative sliding and rocking among the drums. As assessed by previous studies [11], low-frequency earthquakes led to prevalent rocking, while high-frequency earthquakes led to significant sliding. Indeed, as an example, Figure 6 shows the displacements and velocities at the capital and base of the column under the Iprinia-Sturno and Edessa records. Figure 7 shows the failure process of the column within the last four seconds until the collapse. Both the records led to the collapse of the capital and two drums. However, the IrpiniaSturno record initially induced the rocking of the entire column as a single block, then the failure process involved the rocking of the last two drums and the capital without permanent displacements 
in the standing part of the column. The second input (i.e. Edessa) induced relative sliding between the drums, other than rocking. Unlike the first case, permanent relative displacements were produced.
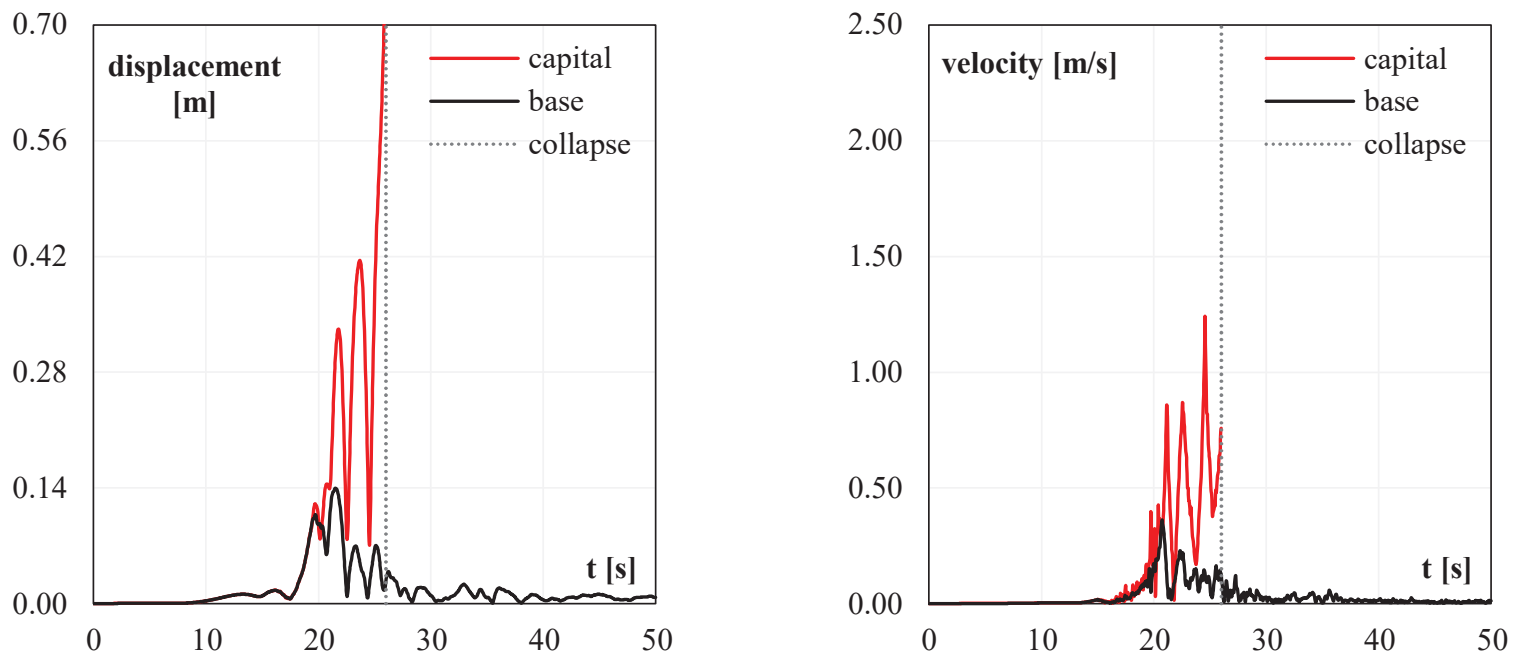

(a)
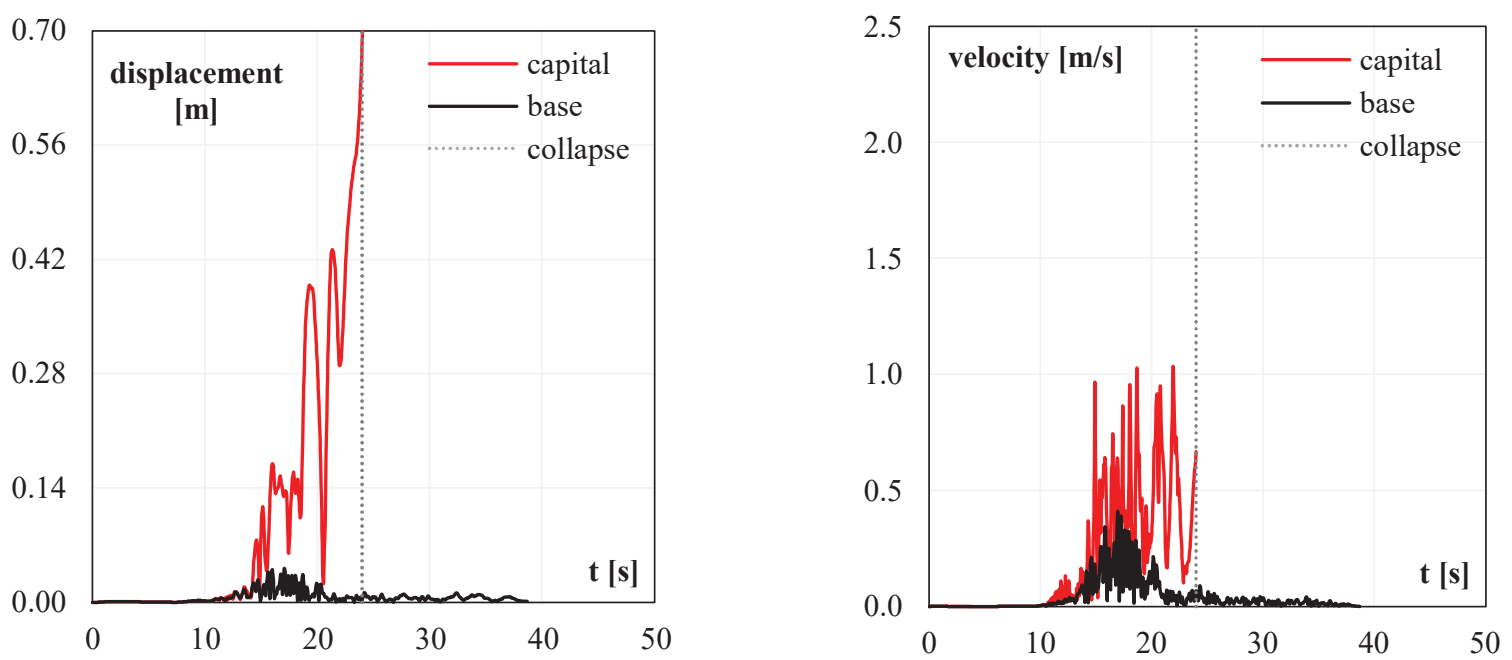

(b)

Figure 6: Displacements and velocities at the capital and base of the column under the Irpinia-Struno (a) and Edessa (b) input motions.

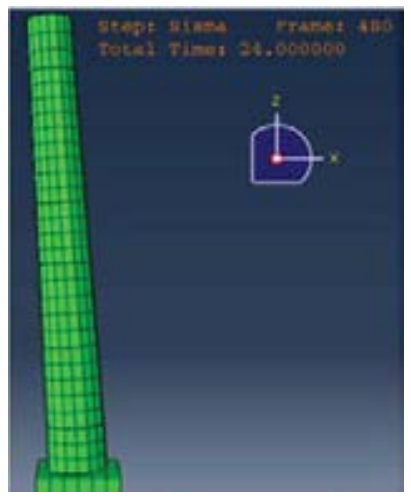

$t=24 s$

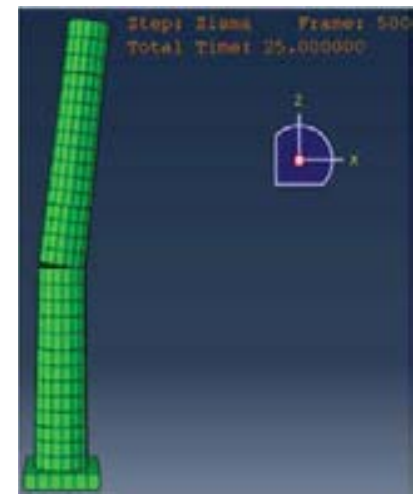

$\mathrm{t}=25 \mathrm{~s}$

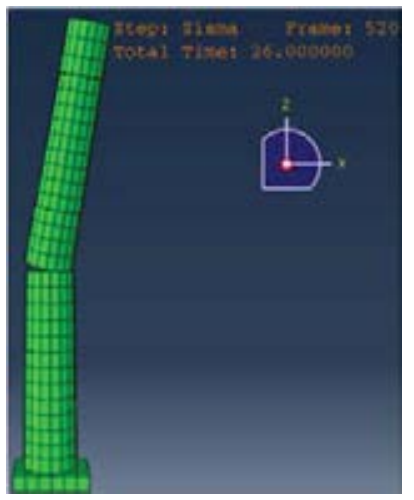

$t=26 s$

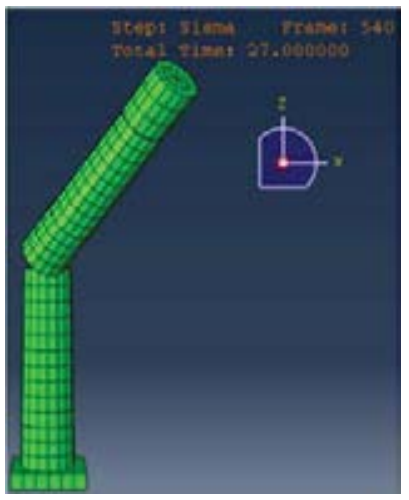

$\mathrm{t}=27 \mathrm{~s}$

(a) 


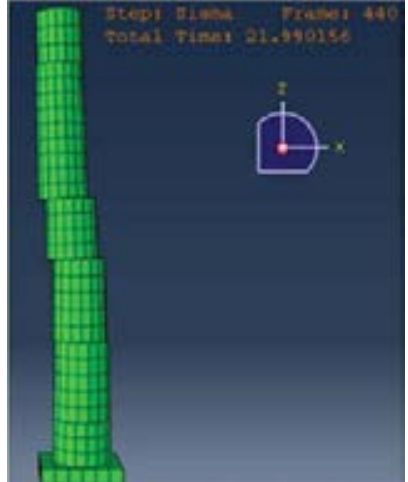

$\mathrm{t}=22 \mathrm{~s}$

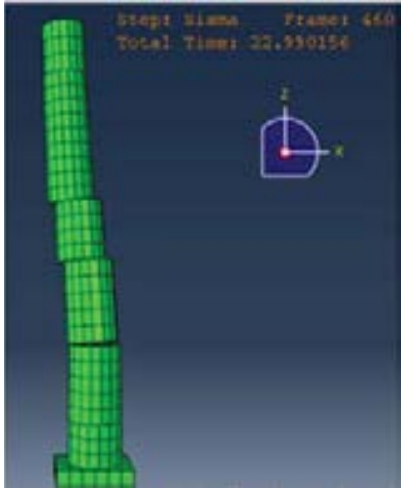

$\mathrm{t}=23 \mathrm{~s}$

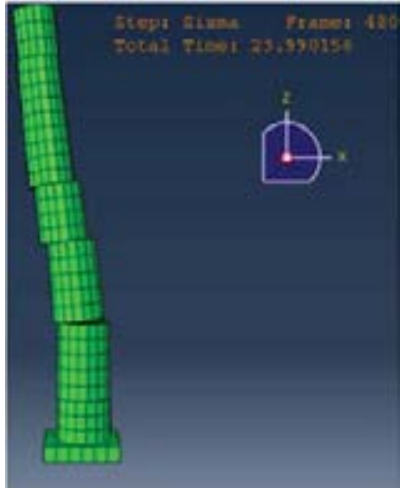

$\mathrm{t}=24 \mathrm{~s}$

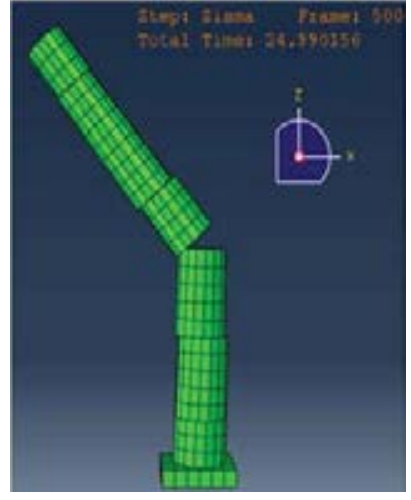

$\mathrm{t}=25 \mathrm{~s}$

(b)

Figure 7: Failure process of the column under the Irpinia-Struno (a) and Edessa (b) input motions.

\section{CONCLUSIONS}

This paper presents a part of a wide study focused on the investigation of the seismic stability of multidrum free-standing tuff columns at the Pompeii archeological site. The study involved, at first, extensive surveys and visual inspection aimed at the knowledge of the main geometrical properties and most common forms of degradation of such structures at the site. The study involved 103 greytuff columns from four different areas of the site in private and public areas, selected as representative of typical column-type at the site. A study of the seismic behavior of one column from the tetrastyle atrium of Casa del Fauno was performed. This structure was selected for the analyses since it showed a high level of degradation and needed specific and urgent actions. The study was carried out based on the Finite Element Method (FEM). The performed investigations led to the following main conclusions:

- A considerable number of the surveyed columns were incomplete with missing parts, while 55 out of 103 columns were completely preserved;

- The main geometrical parameters of complete columns, affecting their seismic behavior ranged between: mean aspect ratio, $\mathrm{H} / \mathrm{d}, 7.27 \mathrm{~m}-8.53 \mathrm{~m}$; mean distance from the center of mass of the column to the base perimeter, $\mathrm{R}, 1.59 \mathrm{~m}-2.82 \mathrm{~m}$; mean number of drums was equal to 5 or 6 ;

- Eight seismic records with different frequencies and amplitudes were selected for the numerical analyses aimed at investigating one multidrum column seismic behavior; the minimum scale factors applied to the intensities of the seismic records producing the collapse of the column was determined;

- Two seismic records with the higher predominant periods were found to be most dangerous, leading to the collapse with the minimum critical intensity measures, PHA. These intensity values at the collapse fall into and below the range of expected values derived from the Italian seismic zoning;

- The studied column showed different dynamic responses for the different input motions, with low-frequency records leading to prevalent rocking and high-frequency ones leading to significant sliding and permanent relative displacements among the drums.

Information on the geometrical properties and the state of preservation of typical archaeological multidrum columns are useful for the assessment of the seismic vulnerability of these structural elements. Further research could be performed to assess the effect of different geometrical properties of the structures on their seismic behavior (i.e. slenderness and size of the column and number and size of the drums) and different forms of degradation, particularly considering the presence of cracks, missing portions, eroded surfaces, permanent relative displacements between the drums and/or uneven profile of the column. 


\section{ACKNOWLEDGMENTS}

The authors acknowledge the former director of Parco Archeologico di Pompei (PAP), Prof. Massimo Osanna and Arch. Annamaria Mauro for the support provided to this research. We would also like to thank Mr. Andrea Torre for his undergraduate thesis on the research topic presented in the paper and for his collaboration on the development of the analyses.

\section{REFERENCES}

[1] G.W. Housner, The behavior of inverted pendulum structures during earthquakes, Bull. Seismol. Soc. Am. 53 (1963) 403-417. https://doi.org/10.1017/CBO9781107415324.004.

[2] I.N. Psycharis, Dynamic behaviour of rocking two-block assemblies, Earthq. Eng. Struct. Dyn. 19 (1990) 555-575.

[3] P.D. Spanos, P.C. Roussis, N.P.A. Politis, Dynamic analysis of stacked rigid blocks, Soil Dyn. Earthq. Eng. 21 (2001) 559-578. https://doi.org/10.1016/S0267-7261(01)00038-0.

[4] G. Minafò, G. Amato, L. Stella, Rocking Behaviour of Multi-Block Columns Subjected to Pulse-Type Ground Motion Accelerations, Open Constr. Build. Technol. J. 10 (2016) 150-157. https://doi.org/10.2174/1874836801610010150.

[5] M.J. DeJong, E.G. Dimitrakopoulos, Dynamically equivalent rocking structures, Earthq. Eng. Struct. Dyn. 43 (2014) 1543-1563. https://doi.org/10.1002/eqe.2410.

[6] H.P. Mouzakis, I.N. Psycharis, D.Y. Papastamatiou, P.G. Carydis, C. Papantonopoulos, C. Zambas, Experimental investigation of the earthquake response of a model of a marble classical column, Earthq. Eng. Struct. Dyn. 31 (2002) 1681-1698. https://doi.org/10.1002/eqe.184.

[7] V. Drosos, I. Anastasopoulos, Shaking table testing of multidrum columns and portals, Earthq. Eng. Struct. Dyn. 43 (2014) 1703-1723. https://doi.org/10.1002/eqe.2418.

[8] K. Papadopoulos, E. Vintzileou, I.N. Psycharis, Finite element analysis of the seismic response of ancient columns, Earthq. Eng. Struct. Dyn. 48 (2019) 1432-1450. https://doi.org/10.1002/eqe.3207.

[9] V. Sarhosis, G.P. Lignola, P.G. Asteris, Seismic Vulnerability of Ancient Colonnade, in: Civ. Environ. Eng., IGI Global, 2016: pp. 950-974. https://doi.org/10.4018/978-1-4666-96198.ch041.

[10] A. Pappas, F. da Porto, C. Modena, Seismic vulnerability assessment form for free-standing columns based on a simplified numerical analysis, Int. J. Archit. Herit. 10 (2016) 15583058.2015.1113336. https://doi.org/10.1080/15583058.2015.1113336.

[11] I.N. Psycharis, J. V. Lemos, D.Y. Papastamatiou, C. Zambas, C. Papantonopoulos, Numerical study of the seismic behaviour of a part of the Parthenon Pronaos, Earthq. Eng. Struct. Dyn. 32 (2003) 2063-2084. https://doi.org/10.1002/eqe.315.

[12] I.N. Psycharis, Seismic Vulnerability of Classical Monuments, in: Recent Adv. Earthq. Eng. Eur. 16th Eur. Conf. Earthq. Eng., Thessaloniki, Greece, 2018: pp. 563-582. https://doi.org/10.1007/978-3-319-75741-4_24.

[13] K. Pitilakis, E. Tavouktsi, Seismic Response of the Columns of Two Ancient Greek Temples in Rhodes and Lindos, 8th Int. Symp. Conserv. Monum. Mediterr. Basin, Patra. (2010) Vol. 31. http://library.tee.gr/digital/m2616/m2616_pitilakis.pdf.

[14] Italian Presidency of the Council of Ministers, Ordinance n. 3519. Criteri generali per l'individuazione delle zone sismiche e per la formazione e l'aggiornamento degli elenchi delle medesime zone, G.U. n.108 del 11/05/2006, (2006). 